Revista Brasileira de Farmacognosia Brazilian Journal of Pharmacognosy 21(4): 674-679, Jul./Aug. 2011

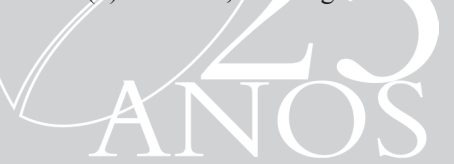

Article

Received 20 Oct 2010

Accepted 11 Dec 2010

Available online 10 Jun 2011

Keywords:

brown seaweed

fucoidan

sulfated polysaccharide

toxicological assessment

ISSN 0102-695X

doi: $10.1590 / \mathrm{S} 0102-695 \mathrm{X} 2011005000098$

\section{Evaluation of acute and subchronic toxicity of a non-anticoagulant, but antithrombotic algal heterofucan from the Spatoglossum schröederi in Wistar rats}

\author{
Jailma Almeida-Lima, ${ }^{1}$ Nednaldo Dantas-Santos, ${ }^{1}$ Dayanne L. \\ Gomes, ${ }^{1}$ Sara L. Cordeiro, ${ }^{1}$ Diego A. Sabry, ${ }^{1}$ Leandro S. Costa, ${ }^{1,4}$ \\ Maria de L. Freitas, ${ }^{2}$ Naisandra B. Silva, ${ }^{2}$ Carlos E. B. Moura, ${ }^{2}$ \\ Telma M. A. M. Lemos, ${ }^{3}$ Edda L. Leite, ${ }^{1}$ Hugo A. O. Rocha ${ }^{*}$,
}

\author{
${ }^{1}$ Departamento de Bioquímica, Universidade Federal do Rio Grande do Norte, Brazil, \\ ${ }^{2}$ Departamento de Morfologia, Universidade Federal do Rio Grande do Norte, Brazil, \\ ${ }^{3}$ Departamento de Análises Clínicas e Toxicológicas, Universidade Federal do Rio \\ Grande do Norte, Brazil, \\ ${ }^{4}$ Instituto Federal de Educação, Ciência e Tecnologia do Rio Grande do Norte, Campus \\ Santa Cruz, Brazil.
}

\begin{abstract}
Fucan is a term used to denominate a family of sulfated polysaccharides rich in L-fucose. The brown alga Spatoglossum schröederi, Dictyotaceae, synthesizes three heterofucans named A, B, and C. Fucan A is a non-anticoagulant heterofucan which possesses potent antithrombotic (in vivo) and antiproliferative (in vitro) activities. However, its toxicity in vivo has not been determined. The present study examined the acute and subchronic toxicity of the fucan A in Wistar rats after subcutaneous administration. After that, the animals were killed and examined. The results showed in the acute study that fucan A did not cause general adverse effects and mortality in the concentrations $0,20,100,1000$, and $2000 \mu \mathrm{g} / \mathrm{g}$ body weight per rat for seven days. Regarding the subchronic study, the data showed that the fucan A did not cause any change in hematological and biochemistry parameters, as well as in the morphology, and in the size of the rat's organs analyzed at a concentration of $20 \mu \mathrm{g} / \mathrm{g}$ body weight per rat during a 62-day period. In conclusion, this study indicates this heterofucan is a compound with potential pharmacological value that has no toxicity in vivo.
\end{abstract}

\section{Introduction}

The general sulfated polysaccharides of brown seaweeds are called fucans, which comprise families of polydisperse molecules based on sulfated L-fucose; heterofucans are also called fucoidans (Rocha et al., 2005a; Bilan et al., 2008). Fucans from algae express important pharmacological activities such as anticoagulant, antioxidant, antiproliferative, antitumoral, anticomplementary, anti-inflammatory, antiviral, antipeptic, and antiadhesive activities (Rocha et al., 2005b; Cumanshi et al., 2007; Li et al., 2008; Costa et al., 2010). In spite of several studies on the biological activities of fucans, detailed studies on the toxicology of fucans from different sources are limited. Few studies have shown that some algal fucans are not toxic compounds ( $\mathrm{Li}$ et al., 2005; Gideon \& Rengasamy, 2008; Zaragozá et al., 2008; Chung et al., 2010). However, each new fucan purified from a marine alga is a new compound with unique structures and, consequently, with potential pharmacological and toxicological properties.

The brown alga Spatoglossum schröederi, Dictyotaceae, synthesizes three heterofucans (Rocha et al., 2005a), the polysaccharide - namely fucan A - is the most abundant heterofucan produced by this alga (Leite et al., 1998). This compound is practically devoid of anticoagulant activity in vitro and hemorrhagic activity in vivo, but when fucan A was injected endovenously $24 \mathrm{~h}$ before the ligature of the venae cavea, it showed a dose-dependent antithrombotic effect, reaching saturation around $20 \mu \mathrm{g} / \mathrm{g}$ of rat weight. In addition, this effect was also time-dependent, reaching saturation around $16 \mathrm{~h}$ after fucan administration. Besides, regardless of administration pathway, fucan A displayed antithrombotic action, the exception was the oral pathway (Barroso et al., 2008). These data suggest that it may be an ideal antithrombotic agent in vivo. Earlier, 
we showed fucan $\mathrm{A}$ as an antiproliverative compound against several tumor cell lines which did show genotoxic and mutagenic effects in vitro (AlmeidaLima et al., 2010). However, information about fucan A toxicity in vivo is not available compared with that of other fucans. On the basis of these considerations, the purpose of the present study was to investigate the toxic effects of fucan A extracted from S. schröederi.

\section{Materials and Methods}

\section{Algal material}

The brown seaweed Spatoglossum schröederi, Dictyotaceae, (voucher specimen number 1976) was collected on the seashore of Natal, RN, Brazil. Immediately after collection, the alga was dried at 50 ${ }^{\circ} \mathrm{C}$ under ventilation and grounded in a blender. The seaweed was then treated with acetone to eliminate lipids and pigments.

\section{Extraction of fucans}

Using a methodology which combined proteolysis and sequential acetone precipitation we obtained seven polysaccharides fractions from the brown seaweed S. schröederi (Barroso et al. 2008). After electrophoresis, the fraction precipitated with 0.6 volumes of acetone showed fucan A as a major compound. The polysaccharides from 0.6 vol. acetone fraction were further purified by ion exchange chromatography. Fraction eluted with $1.0 \mathrm{M} \mathrm{NaCl}$ which contains fucan A as described by Leite el al. (1998) was then subjected to Sephadex G-75 chromatography which revealed the presence of a single component. Fractions 65-82 eluted from the column were pooled, concentrated, and subjected to electrophoresis in agarose gel.

\section{Animals}

Male Wistar rats (250-300 g) were housed at a temperature of $22 \pm 3{ }^{\circ} \mathrm{C}$ under a $12 \mathrm{~h}$ light/dark cycle and given a standard pelleted diet and water ad libitum during the experimental period. The protocol for these experiments was approved by the Committee of Ethics in Research of the Hospital Universitário Onofre Lopes (HUOL, UFRN) under approval number 082/07.

\section{Acute toxicity study}

The rats were divided into groups of six. Fucan A was dissolved in saline and administered subcutaneously at doses of $0,20,100,1000$, and 2000 $\mu \mathrm{g} / \mathrm{g}$ body weight per rat $(500 \mu \mathrm{L})$. The control group received the same volume of sterile saline. Toxicity symptoms and mortality were observed. After 7-days the animals from each group were weighed, anesthetized with $10 \mathrm{mg} / \mathrm{kg}$ xylazine and $90 \mathrm{mg} / \mathrm{kg}$ ketamine i.m., and bled by cardiac puncture and autopsied to analyze the biochemical, hematological, and histopathological alterations induced by fucan $\mathrm{A}$.

\section{Subchronic toxicity study}

Twelve healthy rats were selected for the test and equally distributed into two groups (six rats per group). Only the concentration of $(20 \mu \mathrm{g} / \mathrm{g}$ body weight per rat, $500 \mu \mathrm{L}$ ) was used for the subchronic toxicity study because this concentration had greater antithrombotic activity in another study (Barroso et al., 2008) and $500 \mu \mathrm{L}$ of saline solution $(0.09 \%)$, for both treated and control group, respectively, were administered daily by subcutaneous route to each rat for 62 consecutive days. The control animals received equal volumes of saline via the same administration route of the treated.

\section{Body weight and organ weight gain}

Individual body weights were recorded once weekly during the study period. Mean body weight gains were calculated for each group during the testing interval (days 1-62). Animals were also weighed immediately after euthanasia for calculation of weight of the organs.

\section{Necropsy and histopathology}

At necropsy, all the animals were killed by anesthetic with xylazine and ketamine. The principal organs (kidneys, spleen, liver, testicle, prostate, heart, brain and lungs) were carefully examined macroscopically and then weighed. Histological examinations (Gideon \& Rengasamy, 2008) were performed on the preserved organs and tissues of the animals from the control group and treated with fucan $\mathrm{A}$. The organs were fixed, trimmed, processed, embedded in paraffin, sectioned ( $5 \mu \mathrm{m}$ diameter), placed on glass microscope slides, and stained with hematoxylin and eosin.

\section{Clinical observations}

All animals were observed three times daily for mortality in studies, acute toxicity, and sub-chronic toxicity. Cage-side observations were made daily during the study and all abnormal findings were recorded. All observations included, but were not limited to: changes in skin, eyes, and mucous membranes, occurrence of secretions and excretions, and autonomic activity (e.g., 
lacrimation, pilo-erection, unusual respiratory pattern). Aberrant behavior (e.g., self-mutilation, walking backwards) were also recorded.

\section{Hematological and clinical biochemistry}

Hematological examination was performed using an automatic hematology analyzer (Horiba ABX Micros 60) to measure the following parameters: hematocrit, hemoglobin, erythrocytes, mean corpuscular volume (MCV), mean corpuscular hemoglobin $(\mathrm{MCH})$, mean corpuscular hemoglobin concentration (MCHC), and leukocyte and platelet count. Clinical biochemicals parameters were analyzed as described early (Messias et al., 2010). The parameters measured with an automated biochemical analyzer (BIOPLUS 2000) were total protein (TP), albumin (Alb), total bilirubin (T. Bil), aspartate aminotransferase (AST), alanine aminotransferase (ALT), $\gamma$-glutamil transferase (GGT), total cholesterol (TC), urea, creatinine (Cr), and glucose.

\section{Statistical analysis}

The values were expressed as mean \pm standard error (S.E.). The statistical analysis of data was by Mann-Whitney test (comparing the treated groups to control) using a 5\% level of significance. The statistical program used was GraphPad Prism software version 3.05 .

\section{Results}

\section{Acute toxicity study}

No animals died during the experimental period, and fucan A did not produce toxic signs in any animals. In addition, the findings of gross necropsy performed at study termination did not reveal any signs of toxicity (data not shown). Under the conditions of this acute test, the LD50 value for fucan A was greater than $2000 \mu \mathrm{g} / \mathrm{g}$ body weight.

\section{Subchronic toxicity study}

\section{Body and organ weights}

No toxicologically significant changes were observed in the biochemical or hematological parameters (Table 1). Post-mortem examination did not reveal pathologic changes in organs and tissues that were related to administration of the test compound. No correlation between the dose level of fucan A and alterations in organ weights were observed; mean body weight of rats was measured weekly. The relative body weights and organ weights are shown in Figure 1 and 2, respectively. Fucan A treatment did not alter body weight in either of the groups treated and no alterations were revealed in any of the organs examined by gross necropsy.

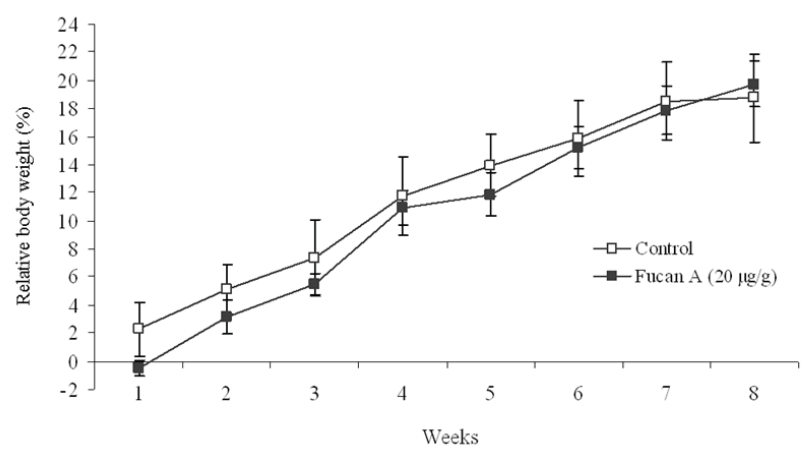

Figure 1. Effect of fucan A administered by subcutaneous injection for 62 days in sub-chronic toxicity study on relative body weight ( $\mathrm{g} / 100 \mathrm{~g}$ body weight) in male Wistar rats. $(\mathrm{n}=6$, per group), data expressed as mean $\pm \mathrm{SE}$.

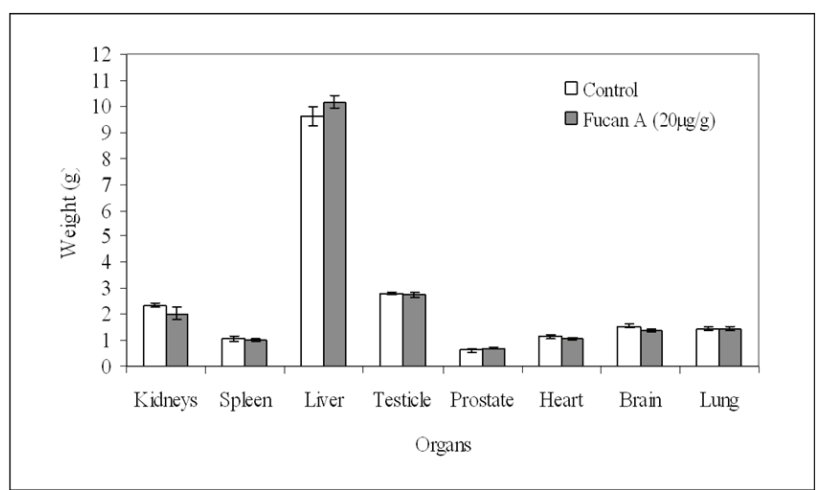

Figure 2. Organ weights in Wistar rats treated with fucan A for 62 days in sub-chronic toxicity study. ( $n=6$, per group), data expressed as mean $\pm \mathrm{SE}$.

\section{Clinical observations}

The results of individual clinical examinations in both the treated and control groups of the male Wistar rats indicate that fucan $\mathrm{A}$ was well tolerated during the treatment period (62-days), with no mortality or signs of morbidity observed. In addition, observations were made daily during the study and no differences between treated rats and controls in changes in skin, eyes, and mucous membranes, occurrence of secretions and excretions, and autonomic activity, as well as in behavioral changes.

\section{Hematological and clinical biochemistry}

The data from the hematological and serum biochemical examinations are summarized in Table 1. Although not statistically significant $(p>0.05)$ increases 
in glucose $(25 \%)$, urea $(30 \%)$, AST $(22.45 \%)$ and TC $(21.26 \%)$ were sporadic at the dose $(20 \mu \mathrm{g} / \mathrm{g}$ body weight/day); however, the differences did not exceed the maximum of physiological and historical control data ranges (140-261 $\mathrm{mg} / \mathrm{dL} ; 12.6-33 \mathrm{mg} / \mathrm{dL} ; 54-$ $298 \mathrm{U} / \mathrm{L} ; 26-82.4 \mathrm{mg} / \mathrm{dL}$, for glucose, urea, AST, and $\mathrm{TC}$, respectively). In relation to the hematological parameters, similar data were observed for the values of the control group; the effects were considered to be of no toxicological significance $(p>0.05)$.

Table 1. Biochemical and hematological parameters of Wistar rats treated with fucan A from S. schröederi for 62 days.

\begin{tabular}{ccc}
\hline Parameters & Control & Fucan A $(20 \mu \mathrm{g} / \mathrm{g})$ \\
\hline Glucose $(\mathrm{mg} / \mathrm{dL})$ & $193.83 \pm 17.41$ & $243.83 \pm 11.54$ \\
Urea $(\mathrm{mg} / \mathrm{dL})$ & $39.33 \pm 3.77$ & $51.33 \pm 3.53$ \\
Creatinine $(\mathrm{mg} / \mathrm{dL})$ & $0.75 \pm 0.10$ & $0.81 \pm 0.12$ \\
AST $(\mathrm{U} / \mathrm{L})$ & $123.17 \pm 6.88$ & $150.83 \pm 12.81$ \\
ALT $(\mathrm{U} / \mathrm{L})$ & $82.33 \pm 6.92$ & $86.67 \pm 8.07$ \\
GGT $(\mathrm{U} / \mathrm{L})$ & $2.50 \pm 0.76$ & $2.00 \pm 0.37$ \\
TP $(\mathrm{g} / \mathrm{L})$ & $6.10 \pm 0.39$ & $5.27 \pm 0.20$ \\
Albumin $(\mathrm{g} / \mathrm{L})$ & $2.22 \pm 0.21$ & $2.12 \pm 0.05$ \\
Globulin $(\mathrm{g} / \mathrm{L})$ & $3.88 \pm 0.36$ & $3.02 \pm 0.16$ \\
TC $(\mathrm{mg} / \mathrm{L})$ & $57.17 \pm 6.05$ & $69.33 \pm 1.26$ \\
TB $(\mathrm{mg} / \mathrm{L})$ & $1.73 \pm 0.17$ & $1.87 \pm 0.17$ \\
Hematocrit $(\%)$ & $42.08 \pm 1.45$ & $36.90 \pm 1.77$ \\
Hemoglobin $\left(\mathrm{g} / \mathrm{dL}^{2}\right)$ & $13.95 \pm 0.43$ & $12.60 \pm 0.61$ \\
Erythrocytes $\left(10^{6} / \mathrm{mm}^{3}\right)$ & $5.92 \pm 0.06$ & $6.07 \pm 0.21$ \\
MCV (fL) & $50.17 \pm 1.47$ & $50.83 \pm 0.31$ \\
MCH (pg) & $16.57 \pm 0.66$ & $16.32 \pm 1.67$ \\
MCHC $(\mathrm{g} / \mathrm{dL})$ & $33.13 \pm 0.40$ & $35.42 \pm 0.44$ \\
Leukocytes $\left(10^{3} / \mathrm{mm}^{3}\right)$ & $7.38 \pm 0.72$ & $4.92 \pm 1.10$ \\
Platelets $\left(10^{3} / \mathrm{mm}^{3}\right)$ & $418.67 \pm 24.74$ & $456.33 \pm 65.37$ \\
\hline
\end{tabular}

Data are presented as mean \pm SE of six animals per group. Abbreviations: AST, aspartate aminotransferate; ALT, alanine aminotransferase; GGT, $\gamma$-glutamil transferase; TP, total protein; TC, total cholesterol; TB, total bilirubin; MCV, mean corpuscular volume; $\mathrm{MCH}$, mean corpuscular hemoglobin; $\mathrm{MCHC}$, mean corpuscular hemoglobin concentration $(p>0.05)$.
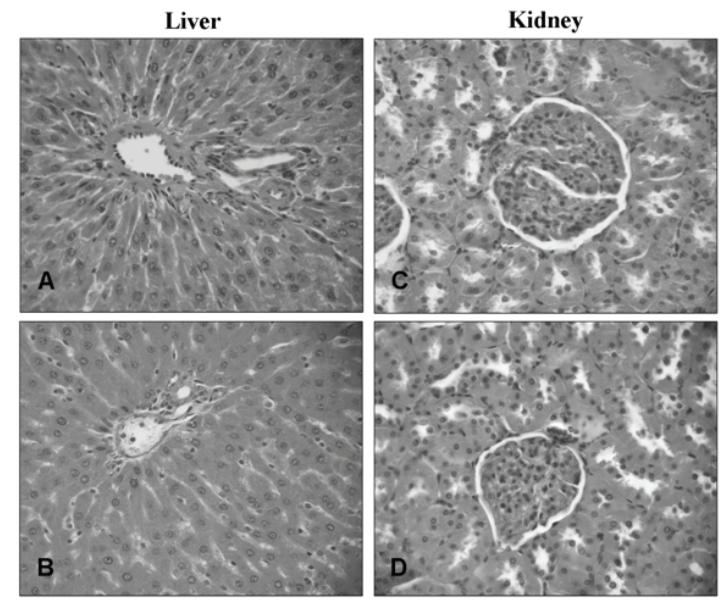

Figure 3. Effect of fucan A on the sub-chronic toxicity study on histological morphology of rat liver (A and B) and kidney (C and D) shown by hematoxylin and eosin staining (x 400): (A and C) group control and (B and D) Fucan A (20 $\mu \mathrm{g} / \mathrm{g}$ ). 
An earlier study from our group with fucan A extracted from the seaweed brown $S$. schroederi suggests that fucan A presents no toxicity in several in vitro tests (Almeida-Lima et al., 2010). In the present studies, the acute and subchronic toxicity of the fucan A administered to Wistar rats was investigated.

In this study, no acute mortality of Wistar rats was observed, indicating that the LD50 of fucan A is more than $2000 \mu \mathrm{g} / \mathrm{g}$. In addition, the subchronic toxicity of fucan A (20 $\mu \mathrm{g} / \mathrm{g}$ for 62-days) also resulted in no mortality, nor in changes in body and organ weights (Figure 1 and 2).

Only the concentration of $20 \mu \mathrm{g} / \mathrm{g}$ was used for the subchronic toxicity study because this concentration had greater antithrombotic activity in another study (Barroso et al., 2008). In regard to the hematological analysis, no significant differences were observed for most of the parameters between the control group and the group treated with fucan A. As to biochemical parameters, the increase in glucose, urea, and AST could be interpreted as treatment-related. However, this seems to have no toxicological significance because the change was small and within the control ranges in contemporary subchronic toxicity studies performed with fucans (Li et al., 2005; Gideon \& Rengasamy et al., 2008; Kim et al., 2010).

Through histopathological analyses, this study also evaluated the integrity of the all organs in Wistar rats subjected to fucan A treatment. In addition, we did not observe modifications of liver and kidney tissues. In addition, there were no alterations in enzymatic activity of ALT and GGT and in the levels of creatinine and total protein of the peripheral blood from treated rats, suggesting a normal function of the liver and kidneys (Figure 3 and Table 1).

Several articles have recommended primary anticoagulant/antithrombotic compounds for all cancer patients admitted to the hospital for surgical or medical reasons (Lee, 2010). Previously, we showed fucan A to be an antithrombotic compound that exhibits a tumor cell proliferation-inhibition effect against pancreatic carcinoma, prostatic cancer epithelial, promyelocytic leukemia, and cervical adenocarcinoma cells. In addition, this polymer did not show genotoxic and mutagenic effects in vitro (Almeida-Lima et al., 2010). Here, this study demonstrates that fucan A showed no toxicity even at high doses after subcutaneous administration in rats for seven days. Furthermore, fucan A was not toxic when administered for 62 days, not causing biochemical, hematological and histopathological alterations. These data led us to propose fucan A as a promising new and safe antithrombotic and antitumoral drug. Moreover, our findings indicate that further investigation is needed to evaluate fucan A activity in tumor progression in vivo.

\section{Acknowledgements}

This study was supported by grants from Conselho Nacional de Desenvolvimento Científico e Tecnológico, Ministério de Ciência e Tecnologia and Coordenação de Aperfeiçoamento de Pessoal de Nível Superior. JAL, SL, and DG are the recipient of a fellowship from CAPES and HR, NDS and DS are recipients of a fellowship from $\mathrm{CNPq}$.

\section{References}

Alekseyenko TV, Zhanayeva SY, Venediktova AA, Zvyagintseva TN, Kuznetsova TA, Besednova NN, Korolenko TA 2007. Antitumor and antimetastatic activity of fucoidan, a sulfated polysaccharide isolated from the Okhotsk Sea Fucus evanescens brown alga. Bull Exp Biol Med 143: 730-732.

Almeida-Lima J, Costa LS, Silva NB, Melo-Silveira RF, Silva FV, Cansanção Felipe MB, Batistuzzo Medeiros SR, Leite EL, Rocha HA 2010. Evaluating the possible genotoxic, mutagenic and tumor cell proliferationinhibition effects of a non-anticoagulant, but antithrombotic algal heterofucan. J Appl Toxicol 30: 708-715.

Barroso EM, Costa LS, Medeiros VP, Cordeiro SL, Costa MS, Franco CR, Nader HB, Leite EL, Rocha HA 2008. A non-anticoagulant heterofucan has antithrombotic activity in vivo. Planta Med 74: 1-7.

Bilan MI, Vinogradova EV, Tsvetkova EA, Grachev AA, Shashkov AS, Nifantiev NE, Usov AI 2008. A sulfated glucuronofucan containing both fucofuranose and fucopyranose residues from the brown alga Chordaria flagelliformis. Carbohydr Res 343: 2605-2612.

Chung HJ, Jeun J, Houng SJ, Jun HJ, Kweon DK, Lee SJ 2010. Toxicological evaluation of fucoidan from Undaria pinnatifida in vitro and in vivo. Phytother Res 24: 1078-1083.

Costa LS, Fidelis GP, Cordeiro SL, Oliveira RM, Sabry DA, Câmara RB, Nobre LT, Costa MS, Almeida-Lima J, Farias EH, Leite EL, Rocha HA 2010. Biological activities of sulfated polysaccharides from tropical seaweeds. Biomed Pharmacother 64: 21-28.

Cumashi A, Ushakova NA, Preobrazhenskaya ME, D'Incecco A, Piccoli A, Totani L, Tinari N, Morozevich GE, Berman AE, Bilan MI, Usov AI, Ustyuzhanina NE, Grachev AA, Sanderson CJ, Kelly M, Rabinovich GA, Iacobelli S, Nifantiev NE 2007. A comparative study of the anti-inflammatory, anticoagulant, antiangiogenic, and antiadhesive activities of nine different fucoidans from brown seaweeds. Glycobiology 17: 541-552.

De Paula Alves Sousa A, Barbosa PS, Torres MR, Martins AM, Martins RD, de Sousa Alves R, de Sousa DF, Alves CD, Costa-Lotufo LV, Monteiro HS 2008. The renal effects of alginates isolated from brown seaweed Sargassum vulgare. J Appl Toxicol 28: 364-369.

Gideon TP, Rengasamy R 2008. Toxicological evaluation of fucoidan from Cladosiphon okamuranus. J Med Food 11: 638-642.

Kim KJ, Lee OH, Lee HH, Lee BY 2010. A 4-week repeated 
Evaluation of acute and subchronic toxicity of a non-anticoagulant, but antithrombotic algal heterofucan from the Spatoglossum schröederi in Wistar

oral dose toxicity study of fucoidan from the Sporophyll of Undaria pinnatifida in Sprague-Dawley rats. Toxicology 267: 154-158.

Leite EL, Medeiros MGL, Rocha HAO, Farias GGM, Silva LF, Chavante SF, Abreu LRD, Dietrich CP, Nader HB 1998. Structure and pharmacological activities of sulfated xylofucoglucuronan from the alga Spatoglossum schröederi. Plant Sci 132: 215-228.

Li B, Lu F, Wei X, Zhao R 2008. Fucoidan: structure and bioactivity. Molecules 13: 1671-1695.

Li N, Zhang Q, Song J 2005. Toxicological evaluation of fucoidan extracted from Laminaria japonica in Wistar rats. Food Chem Toxicol 43: 421-426.

Lee AYY 2010. The roles of anticoagulants in patients with cancer. Thromb Res 125 Suppl 2: S8-S11.

Lins KO, Bezerra DP, Alves AP, Alencar NM, Lima MW, Torres VM, Farias WR, Pessoa C, de Moraes MO, Costa-Lotufo LV 2009. Antitumor properties of a sulfated polysaccharide from the red seaweed Champia feldmannii (Diaz-Pifferer). J Appl Toxicol 29: 20-26.

Messias JB, Caraciolo MCM, Oliveira IM, Montarroyos UR, Bastos IVGA, Guerra MO, Souza I 2010. Avaliação dos parametros hematológicos e bioquímicos de ratas no segundo terço da gestação submetidos a ação de extrato metanolico de Cereus jamacaru DC., Cactaceae. Rev Bras Farmacogn 20: 478-483.

Rocha HA, Bezerra LC, de Albuquerque IR, Costa LS,
Guerra CM, de Abreu LD, Nader HB, Leite EL 2005a. A xylogalactofucan from the brown seaweed Spatoglossum schröederi stimulates the synthesis of an antithrombotic heparan sulfate from endothelial cells. Planta Med 71: 379-381.

Rocha HA, Moraes FA, Trindade ES, Franco CR, Torquato RJ, Veiga SS, Valente AP, Mourão PA, Leite EL, Nader HB, Dietrich CP 2005b. Structural and hemostatic activities of a sulfated galactofucan from the brown alga Spatoglossum schröederi. An ideal antithrombotic agent? J Biol Chem 280: 41278-41288.

Zaragozá MC, López D, P Sáiz M, Poquet M, Pérez J, PuigParellada $\mathrm{P}$, Màrmol $\mathrm{F}$, Simonetti $\mathrm{P}$, Gardana $\mathrm{C}$, Lerat Y, Burtin P, Inisan C, Rousseau I, Besnard M, Mitjavila MT 2008. Toxicity and antioxidant activity in vitro and in vivo of two Fucus vesiculosus extracts. J Agric Food Chem 56: 7773-7780.

\section{*Correspondence}

Hugo A. O. Rocha

Departamento de Bioquímica, Universidade Federal do Rio Grande do Norte

Av. Senador Salgado Filho, 3000, Lagoa Nova, 59078-900

Natal-RN, Brazil

hugo@cb.ufrn.br

Tel.: +558432153416

Fax: +55 8432119208 